\title{
Vernakularisasi Al-Qur'an di Tanah Bugis: Tinjauan Metodologis Terjemahan Al-Qur'an Karya Anregurutta Yunus Maratan
}

\author{
Mursalim \\ Institut Agama Islam Negeri Samarinda \\ mursalim21270@gmail.com \\ Abbas \\ Institut Agama Islam Negeri Kendari \\ abbas@iainkendari.ac.id
}

\begin{abstract}
The aim of this article is to reveal the vernacular activities of the Qur'an in the South Sulawesi region through the work of the scholars of Bugis. This study focuses specifically on Tafsir alQur'an Al-Karim bi al-Lugah al-Bugisiyah the work written by Yunus Maratan, by testing his methodology and dialectics within the framework of the culture of Bugis. Using a descriptiveanalytical approach, this article shows the findings that this work is an attempt to bridge the alQur'an as an Arabic text with the ordinary Bugis people who do not understand the original language of the al-Qur'an (Arabic). The work is not a literary interpretation, as mainstream tafsir literature, but merely a translation of the Quran combining tarjamah lafziyah and tafsiriyah. The history of Islamic proselytism spread throughout the archipelago, especially in South Sulawesi, also shows that certain local elements, including al-Quran, have been included as a preaching tool. That is why the works of the clerics of Bugis are intertwined with the cultural context of local Islamic culture.
\end{abstract}

Keywords: Vernacularization of the Qur'an; Bugis; AG. Yunus Maratan

\begin{abstract}
Abstrak
Artikel ini bertujuan untuk mengungkap aktivitas vernakularisasi al-Qur'an di wilayah Sulawesi Selatan melalui karya ulama Bugis. Fokus kajian ini dikhususnya pada karya Tafsir al-Qur'an Al-Karim bi al-Lugah al-Bugisiyah yang ditulis oleh AG. Yunus Maratan dengan menguji metolodogi dan dialektikanya dalam bingkai budaya Bugis. Dengan menggunakan pendekatan deskriptif-analitik, artikel ini menunjukkan hasil temuan bahwa karya itu adalah upaya untuk menjembatani antara al-Qur'an sebagai teks yang berbahasa Arab dengan masyarakat Bugis awam yang tidak paham terhadap bahasa asal al-Qur'an (Arab). Adapun secara metodologis karya itu bukanlah sebagai sebuah literatur tafsir seperti literatur-literatur tafsir mainstream, melainkan hanya sebagai sebuah karya terjemahan al-Qur'an yang memadukan antara tarjamah lafziyah dan tafsiriyah. Fenomena itu sekaligus membuktikan bahwa sejarah penyebaran dakwah Islam di Nusantara, khususnya di Sulawesi Selatan sangat fleksibel dengan melibatkan berbagai unsur-unsur lokal sebagai media dakwah, termasuk vernakularisasi al-Qur'an. Itulah sebabnya antara karya ulama Bugis dengan konteks budaya masyarakat saling berkelindan dalam membentuk budaya Islam lokal.
\end{abstract}

\section{Kata Kunci: Vernakularisasi al-Qur'an; Bugis; AG. Yunus Maratan.}

\section{A. Pendahuluan}

Produk terjemahan al-Qur'an ke dalam bahasa lokal atau vernakularisasi ternyata telah menjadi bagian krusial dalam dinamika penyebaran ajaran Islam di Nusantara. Hal itu dibuktikan dengan ditemukannya berbagai karya ulama di Indonesia yang menggunakannya sebagai media dakwah untuk memudahkan masyarakat lokal memahami ajaran Islam. ${ }^{1}$ Salah satu di antaranya adalah karya Tafsir al-Qur'an Al-Karim bi al-Lugah al-Bugisiyah yang

\footnotetext{
${ }^{1}$ Moh Fadhil Nur, "Vernakularisasi Al-Qur'an di Tatar Bugis," Rausyan Fikr: Jurnal Studi Ilmu Ushuluddin dan Filsafat 14, no. 2 (2018): 359-394.
} 
ditulis oleh AG. Yunus Maratan sebagai media untuk memudahkan masyarakat Bugis di Sulawesi dalam memahami ayat-ayat al-Qur'an. Walaupun karya itu berjudul tafsir, namun secara konten, termasuk di dalam produk terjemah. Akan tetapi, bila merujuk ke literaturliteratur Ulüm al-Qur'ān primer, maka ditemukan perdebatan panjang di antara kalangan ualma tentang kebolehannya. Mannā' Khalīl al-Qattān dalam Al-Mabāhīis fì 'Ulūm al-Qur'ān mengklaim keharaman terjemahan Al-Qur'an dalam arti vernakularisasi atau tarjamah harfiah. Menurutnya praktik semacam itu dapat menghilangkan aspek kemukjizatan dari unsur kebahasaan al-Qur' an. ${ }^{2}$ Adapun Al-Zarqānī dalam Manāhil al- 'Irfān fì 'Ulūm al-Qur'ān masih membolehkan hal itu bila tidak melanggar standar dari kaidah-kaidah semantik alQur'an. ${ }^{3}$ Berdasarkan hal itu, maka kajian ini dilakukan untuk menguji standar metodologi yang digunakan oleh AG. Yunus Maratan dalam penyusunan karyanya itu, sehingga dapat diketahui adanya aspek-aspek kebersesuaiannya dengan standar kaidah-kaidah penyajian vernakularisasi yang dibolehkan oleh para ulama di dalamnya.

Kajian tentang vernakularisasi al-Qur'an di tanah Bugis pada dasarnya telah dilakukan oleh beberapa peneliti di antaranya, Moh. Fadhil Nur, ${ }^{4}$ Idham Hamid dan Neny Muthi'atul Awwaliyah.5 Mereka mengkaji tentang peran vernakularisasi al-Qur'an dalam mengoptimalkan penyebaran ajaran Islam di Sulawesi Selatan. Akan tetapi kajian-kajian itu belum sampai pada kajian metodologi vernakularisasi yang diterapkan oleh setiap ulama pada masa itu. Dengan demikian kajian hendak melengkapi kajian tersebut dengan secara spesifik membahas metodologi penyusunan kitab Tafsir al-Qur'an Al-Karim bi al-Lugah al-Bugisiyah yang ditulis oleh AG. Yunus Maratan. Oleh karena itu kajian ini difokuskan pada rumusan masalah berikut; (1) bagaimana AG. Yunus Maratan menyusun kitab Tafsir al-Qur'an AlKarim bi al-Lugah al-Bugisiyah; (2) mengapa penyusunan karya itu penting bagi masyarakat Bugis kala itu?; dan (3) bagaimana hubungan dialektis antara kitab Tafsir al-Qur'an Al-Karim bi al-Lugah al-Bugisiyah dengan dinamika budaya masyarakat Bugis?

Untuk menjawab tiga rumusan masalah itu, maka kajian ini menggunakan desain penelitian kualitatif deskriptif yang berbasis pada kajian produk atau karya sebagai konstruksi wacana penyebaran dakwah ajaran Islam melalui praktik vernakularisasi al-Qur'an di Sulawesi Selatan. Kajian ini berargumen bahwa karya Tafsir al-Qur'an al-Karim bi al-Lugah al-Bugisiyah yang ditulis oleh AG. Yunus Maratan disusun secara sitematis menggunakan bahasa daerah Bugis (lontarak), bukan sebagai produk tafsir, melainkan hanya sebagai produk penerjemahan bahasa lokal. Karya itu disusun tiada lain untuk mempermudah masyarakat lokal non-Arab, sehingga mereka tidak hanya sebatas membacanya sebagai teks kitab suci, melainkan juga dapat memahami makna umum di setiap ayat-ayat al-Qur'an.

\section{B. Biografi Singkat AG. Yunus Maratan}

Anregurutta $^{6}$ (selanjutnya disingkat AG) Yunus Maratan bernama lengkap H.

\footnotetext{
${ }^{2}$ Mannā' bin Khalīl Al-Qațtān, Mabāḥis̉ fì 'Ulūm al-Qur'ān (Riyaḍ: Maktabah al-Ma‘ārif, 2000), 307-308. ${ }^{3}$ Muḥammad 'Abd al-'Aẓim al-Zarqani, Manahil al-Irfān fì 'Ulūm al-Qur'an, Jilid II. (Beirut: Dar al-Fikr, 1996), 93.

${ }^{4}$ Nur, "Vernakularisasi Al-Qur'an Di Tatar Bugis."

${ }^{5}$ Neny Muthi'atul Awwaliyah and Idham Hamid, "Studi Tafsir Nusantara: Kajian Kitab Tafsir AG. H. ABD. Muin Yusuf (Tafsere Akorang Ma’basa Ugi)," Jurnal Studi Alquran dan Tafsir di Nusantara 4, no. 2 (2019): $138-154$.

${ }^{6}$ Kata Anregurutta (AG) bermakna "maha guru/pendidik/guru kami”. Ungkapan ini terdiri dua suku kata dalam bahasa Bugis, yaitu kata "anre" yang memiliki makna; "makanan", yang kemudian ketika ditambah awalan "ma" menjadi kata "manre" yang artinya "makan". Gurutta, yaitu "guru kita" yaitu sebuah ungkapan/sapaan penghormatan. Namun ketika dua suku kata ini bergabung dalam satu ungkapan maka kemudian kata ini menjadi sebuah ungkapan penghormatan yang dipakai di daerah tanah Bugis terhadap orang atau tokoh agama yang dianggap sebagai sosok ulama. Istilah ini sama dengan istilah "kiai” yang dipakai di pulau Jawa atau "Tuang Guru atau Guru" di Pulau Sumatera, Kalimantan, dan NTB. Mursalim, "Pemikiran Tasawuf Anregurutta H.
} 
Muhammad Yunus bin Maratan adalah sosok ulama besar dan kharismatik (tau panrita loppo $)^{7}$ di Wajo dan secara umum di Sulawesi. Beliau dilahirkan pada Jum'at 28 Muharram 1332 H/1914 M. ${ }^{8}$ di kampung Wattang Desa Leppangeng- Belawa, sebuah desa yang berjarak sekitar $51 \mathrm{KM}$ dari kota Sengkang ibukota Kabupaten Wajo Sulawesi Selatan. Beliau wafat pada usia 72 tahun tepatnya pada 22 Juni 1986 M di Makassar.

Ayahnya bernama Yunus Maratan yang juga seorang ulama kharismatik di Belawa dan memiliki ilmu pengetahuan tentang agama Islam yang sangat luas. Dengan kapasitas ilmu yang dimilikinya, beliau diangkat sebagai qā (Qadhi Tua) di daerah Belawa. Semasa kecilnya AG. Yunus dibimbing langsung oleh orang tuanya sendiri hingga ketika berada di Makkah untuk menunaikan ibadah haji. Selain bimbingan langsung dari ayahnya, AG. Yunus belajar pula kepada ulama lain yang berdomisili di Belawa, seperti Andi Mappangewa dan ulama yang ada di daerah lainnya misalnya di Tosora-Sengkang dan Soppeng.

Pendidikan pertama yang ditempuh oleh AG. Yunus adalah di Sekolah Rakyat (SR) di Belawa pada 1921-1927, setelah tamat di SR dibawa oleh orang tuanya ke Makkah, di samping menunaikan ibadah haji, beliau melanjutkan pendidikannya sekitar 1929-1933. Ketika belajar di Makkah AG. Yunus memilih masuk di Madrasah Al-Falah ${ }^{9}$ dan disela-sela waktu luangnya dapat juga mengikuti pengajian khalaqah di Masjid Haram yang disampaikan oleh ulama dari berbagai penjuru dunia.

Setelah pulang dari Makkah, AG. Yunus mendengar kedatangan salah seorang ulama besar yang datang dari Makkah yaitu AG. Puang Aji Sade, maka AG. Yunus melanjutkan petualangan ilmunya di Madrasah Arabiyah Islamiyah (MAI) di Sengkang di bawah bimbingan langsung AG. Sade pada jenjang Madrasah Tsanawiyah pada 1933-1937, dilanjutkan pada tingkat Madrasah Aliyah 1937-1943. Pada 1940-1943 beliau mengikuti kelas takhașșus di bawah bimbingan langsung oleh beberapa ulama, yaitu AG. Sade, Syaikh Idrus, dan AG. H. Muhammad Jafar. ${ }^{10}$

Di sela-sela kesibukannya mengikuti kelas takhassus AG. Yunus diangkat sebagai Qāḍi (1938-1952) di kampung kelahirannya Kecamatan Belawa, sementara beliau juga tetap belajar mengajar meskipun harus berhadapan dengan penguasa pemerintahan Jepang yang melarang pengoperasian madrasah. Pada saat menjabat sebagai qā Masjid Raya Darussalam Belawa, sebuah masjid yang sangat terkenal di Wajo bahkan di Sulawesi Selatan karena kekeramatannya dan juga sebagai pusat untuk memperdalam ilmu agama bagi masyarakat Wajo secara khusus dan masyarakat Sulawesi Selatan secara umum pada $1947 .^{11}$

Abdurrahman Ambo Dalle; Telaah atas Kitab al-Qauwl al-Sādiq, Jurnal Fenomena 7, no. 2 (2015), 171-188.

${ }^{7}$ Tau panrita adalah sebuah sebutan bagi masyarakat Bugis kepada seseorang yang memiliki ilmu agama Islam yang luas dan mumpuni, bukan hanya aspek pengetahuan teoritis tetapi juga aspek amaliyah sehingga menjadi qudwah hasanah (contoh tauladan) di tengah-tangah masyarakat. Sebagaimana dikutip oleh Wahyuddin Halim dalam sebuah makalahnya bahwa to panrita memiliki kemampuan ilmu dalam bidang agama, di dalam tingkah lakunya mencerminkan sikaf bijaksana, jujur dan saleh. Lihat Wahyuddin Halim "Arung, To Panrita, dan Transformasi Otoritas Keagamaan dan Kecendikiwanan di Sulawesi Selatan, "Diskusi Buku Chirstian Pelras, Manusia Bugis, (Jakarta: Nalar 2006), oleh Yayasan Ininnawa: Pusat Kajian Budaya, pada tanggal 14-16 Maret 2006 di UNHAS. Lihat Juga "http://www.ilhamkadir.com/2013/02/gurutta-anreguru-panrita.html”

${ }^{8}$ Kamaluddin Abunawas dan Husnul Fahimah Ilyas, Menguak Cakrawala Perubahan; Kiprah AG. H. M. Yunus Martan dan AG. H. Abdullah Maratan (Yogyakarta: Trusmedia Grafika, 2017), 19.

${ }^{9}$ Banyak pelajar dari Indonesia banyak belajar di Madrasah al-Falah termasuk AG. H. Muh. As'ad alBugisy. Di samping Madrasah al-Falah sebagai tempat menimba para pelajar Nusantara juga ada Madrasah Shaulatiyah yang didirikan oleh ulama imigran dari India yang bernama Syekh Rahmatullah Ibn Khalil al-Hindi al-Dahlawi pada tahun $1292 \mathrm{H}$.

${ }^{10}$ Kamaluddin Abunawas \& Husnul Fahimah Ilyas, Menguak Cakrawala Perubahan; h. 21.

${ }^{11}$ Masjid Raya Darussalam di Belawa adalah sebuah masjid yang memadukan arsitektur Islam dengan Bugis 
Pondok Pesantren As'adiyah merupakan salah satu pondok pesantren yang tertua di Sulawesi Selatan, yang berada di kota Sengkang Kabupaten Wajo. Pada awalnya Pesantren As'adiyah bernama al-Madrasah al-'Arabiyah al-Islamiyah disingkat menjadi MAI, yang didirikan oleh AG. Haji Muhammad As'ad ${ }^{12}$ (yang dikenal oleh kalangan santri As'adiyah dan masyarakat Sulsel dengan panggilan Gurutta Puang Aji Sade) pada Mei 1930, ${ }^{13}$ meskipun awal pembelajaran dengan kegiatan 'mangaji tudang/kitta' (pengajian kitab) sudah ada sejak 1928. Setelah AG. Sade wafat nama MAI diubah menjadi nama "Pesantren As'adiyah" tepatnya pada 9 Mei 1953 ketika di bawah kepemimpinan AG. Daud Ismail, sebagai bentuk penghormatan kepada jasa-jasa AG. Sade. Jadi nama As'adiyah adalah nisbat dari nama pendirinya Muhammad As'ad. ${ }^{14}$ Setelah AG. Sade wafat, pesantren ini dipimpin oleh AG. Daud Ismail pada 1953-1961, kemudian digantikan oleh AG. Yunus Maratan pada tanggal 30 April 1961-1986. Namun sebelum memimpin Pesantren As'adiyah Sengkang beliau sempat mendirikan MAI pada 1947 di Belawa.

Di bawah kepemimpinan AG. Yunus Pesantren As'adiyah mengalami perkembangan yang cukup pesat dengan beberapa terobosan yang dihasilkan oleh beliau. Terlihat dengan perluasan organisasi dengan mendirikan cabang-cabang As'adiyah di berbagai daerah, bukan hanya di Sulawesi Selatan tetapi beberapa provinsi di luar Sulawesi diantaranya Kalimantan Timur, Riau, dan Sulawesi Tenggara. Di samping perluasan organisasi, beliau juga melakukan pembaharuan dalam bidang kurikulum dengan memasukkan pelajaran-pelajaran umum, misalnya matematika, geografi, sejarah dalam pelajaran di madrasah.

Demikian juga pengembangan lembaga pendidikan As'adiyah dilakukan oleh AG. Yunus yaitu dengan membuka tingkat Taman Kanak-Kanak 1965 dan pembukaan Perguruan Tinggi Islam As'adiyah (PTIA) pada tanggal 12 Oktober 1964 M/ 6 Jumadil Akhir 1385 H. Dengan nama Sekolah Tinggi Agama Islam (STAI) As'adiyah, enam tahun kemudian mendapatkan status disamakan dengan SK Menteri Agama No. 52 Tahun 1970. Pada awalnya perguruan tinggi ini hanya membina satu yaitu Fakultas Ushuluddin dengan jurusan Aqidah Filsafat. Namun dengan pesatnya perkembangan saat ini sudah beralih status menjadi Institut Agama Islam (IAI-As'adiyah) Sengkang dengan 4 fakultas yaitu Fakultas Syariah, Ushuluddin, Dakwah, dan Tarbiyah ditambah dengan Program Pascasrjana (S2).

Dalam rangka memperluas cakupan wilayah dakwah As'adiyah yang dikomandoi oleh AG. Yunus, maka pada 1968 didirikanlah suatu pemancar radio yang dikenal "Radio Suara As'adiyah (RSA)". Keberadaan RSA merupakan salah satu bukti bahwa AG. Yunus sebagai seorang ulama yang sangat progresif dan visioner pada masanya yang tidak pernah diduga oleh orang untuk melahirkan sebuah gagasan pada masa itu, padahal perkembangan teknologi di masa itu masih sangat sederhana.

Dengan keberadaan RSA perguruan dan dakwah As'adiyah semakin jauh jangkauan siarannya hingga sampai ke pelosok wilayah Sulawesi Selatan, bahkan sampai menyeberang ke beberapa wilayah Sulawesi Tenggara. Lewat siaran radio ini semua pengajian halaqah (mangaji tudang/kitta'), baik di Masjid Raya Wajo maupun di kantor RSA yang dipimpin

dan masjid ini dianggap oleh masyarakat Sulawesi Selatan sebagai masjid keramat yang dapat memberikan keberkahan bagi pengunjungnya karena dikaitkan dengan sosok wali sufi bernama Syeikh Sagena atau Tosagena. Dapat dibaca dalam berita online "Tribun Timur.com", tanggal 23 Mei 2018, Wahyuddin Halim, "Refleksi Ramadhan; Mengapa Masjid Agung Darussalam Wajo Didatangi Pencari Berkah dari Luar Daerah?

${ }^{12}$ Abd. Kadir M. "Transformasi Kelekturan pada Pesantren As'adiyah" dalam Abd. Aziz Albone (ed.), Transformasi Kelekturan Pesantren di Sulawesi Selatan (Ujung Pandang: Balai Penelitian Lektur Keagamaan, 1993), 15.

${ }^{13}$ Daud Ismail, al-Ta'rif Bi al-Alim al-Allamah al-Syedkh al-Haj Muhammad As'ad al-Buqisi, (Sengkang Wajo, 1956), 2. Aguswandi, “Kontribusi AGH. Muhammad As'ad terhadap Pengembangan Dakwah di Sengkang Kab. Wajo (Suatu Kajian Tokoh Dakwah), Jurnal al-Khitabah V, no. 2, (2018), 126-141.

${ }^{14}$ Daud Ismail, al-Ta'rif...h. 16. 
langsung oleh AG. Yunus dan beberapa guru senior, misalnya AG. Hamzah Badawi, AG. Hamzah Manguluang, AG. Abdullah Maratan, AG. Abdul Kadir, AG. Abunawas Bintang, AG. Ilyas Salewe, dan AG. Muhmamad Hasan. ${ }^{15}$

Secara khusus pengajian setelah shalat Subuh semuanya dibimbing langsung oleh AG. Yunus dan setelah shalat Isya dengan pengajian kitab Mukhtārul Aḥâdìं yang dikhususkan bagi santri tingkat Madrasah Aliyah. Di samping pengajian secara khusus bagi santri Pesantren As'adiyah, AG. Yunus juga menyampaikan pengajian setelah shalat Dzuhur tanpa dihadiri oleh santri dan pengajian ini diperuntukkan bagi masyarakat umum yang disiarkan langsung oleh Radio Suara As'adiyah. Daya tarik pengajian-pengajian AG. Yunus adalah karena menggunakan pengantar bahasa Bugis dengan bahasa yang dikemas dengan bahasa yang sangat sederhana dan halus.

AG. Yunus termasuk ulama yang produktif dengan ditemukannya berbagai karya dalam berbagai bidang ilmu pengetahuan ke-Islaman di antaranya; dalam bidang Fiqh Kitāb al-Janāiz, Al-Shalāt 'Imād al-Dīn, Kitāb al-Nikāh, Kitāb al-Farāidh, Manasik Hajji, Kitāa al-Zakāt, Kitāb al-Shiyām. Bidang Tauhid/Aqidah di antaranya, Al-Firaq al-Islāmiyyah, dan Kitāb al- 'Aqū'id, Asmā' al-Husnā. Bidang Tafsir al-Qur'an di antaranya, Tafsīr al-Qur'ān al-Karìm Juz Amma, Tafsīr al-Qur'ān al-Karìm 3 Juz (Alif Lām Mìm, sampai Tilka al-Rusul), Faḍāl al-Qur'ān, Tafsìr al-Qur'ān bi al-Lugah al-Bügisiyyah. Bidang Hadis Nabi di antaranya Al-Hadīs alMuntakhab, Al-Hadīis al-Muhktārah. Bidang Bahasa di antaranya Kitāb al-Lugah al'Arabiyyah. Bidang Sejarah Islam di antaranya, Gazwah Badar al-Kubrā, Mawlīd al-Barazanjī, Gazwah Handaq, Gazwah Khaibar, Kisah Sulaiman, Kisah Ibrahim, Kisah Nabi Yusuf, Kisah Nabi Musa, Kisah Isra' Mi'raj, Al-Sìrah al-Nabawiyyah. Bidang Akhlak di antaranya, Majmū'ah al-Adab dengan 2 versi bahasa yaitu Arab dan Bugis. ${ }^{16}$ Karya-karya tersebut hampir semuanya ditulis dengan menggunakan pengantar bahasa Bugis, kecuali dalam bidang hadis Nabi dan Bahasa Arab, kedua bidang ini khusus ditulis dengan pengantar bahasa Arab.

\section{Tafsir al-Qur'ān al-Karīm bi al-Lugah Bugisiyyah dan vernakularisasi al-Qur'an C.1. Sekilas tentang Tafsīr al-Qur'ān al-Karīm bi al-Lugah al-Bugīsiyyah}

Kitab ini terbit tiga kali yang dicetak oleh Penerbit Toko Buku dan Percetakan Adil, yang beralamat di Jalan Datuk Sulaiman No. 86 Sengkang Wajo tepatnya depan Masjid Jami' Sengkang. Ukuran kitabnya 14 x $18 \mathrm{~cm}$ dan jumlah halaman adalah 62 halaman. Kitab pertama kali diterbitkan pada tanggal 9 Oktober 1958 M. bertepatan 25 Rabiul Awal $1378 \mathrm{H}$ di Sengkang-Wajo. Sementara terbitan ke-2 tidak didapatkan informasi kecuali yang didapatkan penulis hanya terbitan ke-3, yaitu pada tanggal 4 November 1972 M. bertepatan 27 Ramadhan $1392 \mathrm{H}$ sebagaimana tertulis pada kata muqaddimah kitab ini.

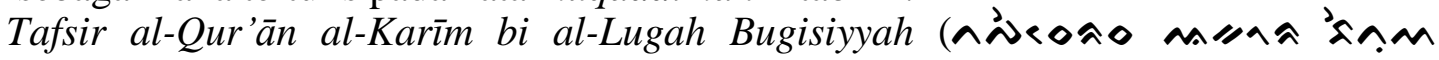

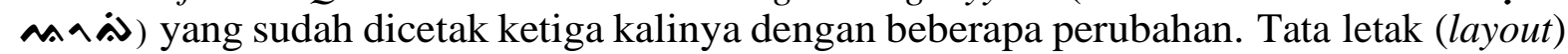
karya tafsir ini didesain dengan menuliskan ayat-ayat al-Qur'an setiap surah berdampingan dengan terjemahannya dengan dua kolom. Kolom sebelah kanan adalah terjemahan dan kolom sebelah kiri adalah teks ayat. Berbeda dengan karya AG. Daud Ismail yang meletakkan teks ayat sebelah kanan dan terjemahan di sebelah kiri. Sebelum diterjemahkan satu kelompok surah, terlebih dahulu disebutkan nama surahnya dengan dua versi bahasa (Arab dan Bugis). Nama surahnya tetap digunakan dengan nama bacaan Arabnya dalam versi tulisan aksara Lontara, misalnya surat al-Fatihah (لفائة ayat-perayat, sebagaimana ditunjukkan pada gambar 1 .

الكري باللغة البويسية، "Judul kitab ini menggunakan dwi bahasa, yaitu bahasa Arab dan Bugis

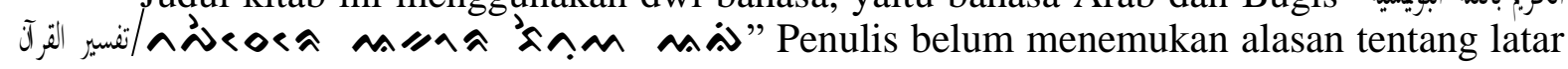

\footnotetext{
${ }^{15}$ Kitab-Kitab yang digunakan dalam pengajian, yaitu Tafsīr al-Jalālain, Riyāọ al-Ṣāliḥinn, Fatḥ al-Mu'īn, Bulūg al-Maram, Isryād al-'Ibad, Tanwīr al-Qulūb, al-Muhażżab, Maw'izat al-Mu'minīn, Syarḥ al-Hikam.

${ }^{16}$ Proyek Pembinaan Perguruan Tinggi Agama IAIN Alauddin Ujung Pandang, Karya Tulis Ulama di Sulawesi Selatan (Ujung Pandang: 1981/1982), 91-98.
} 
belakang penamaan kitab Tafsir al-Qur'an Karìm bi al-Lugah al-Buqisiyyah/Tafesere Akorang Bettuwang Bicara Ugi. Meski di sampul tertulis Bahasa Bugis dan Indonesia, bahasa yang digunakan di dalam penjelasannya adalah semuanya dalam versi bahasa Bugis.

Gambar 1. Contoh penyajian/penulisan kitab

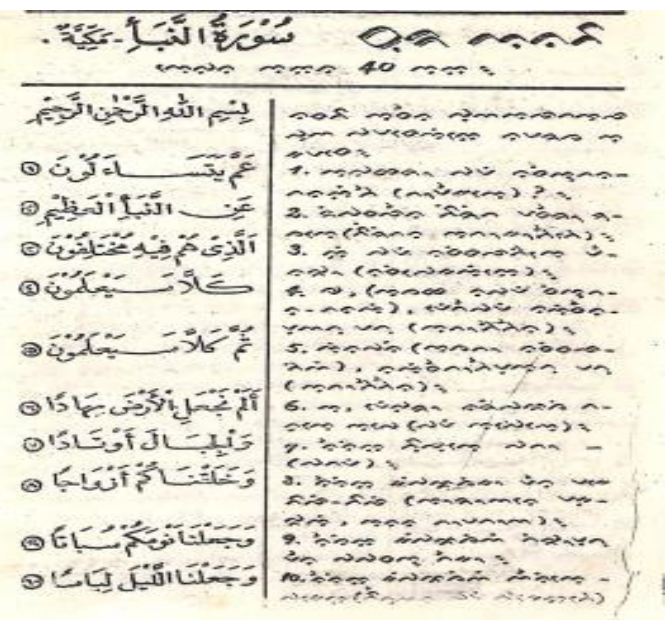

Pemilihan tulisan aksara Lontara' Bugis dalam kitab ini dilatari beberapa alasan, pertama karena aksara lontara' Bugis salah satu aksara daerah di Indonesia yang masih eksis dan masih tetap dipelajari di daerah Sulawesi Selatan sampai sekarang. ${ }^{17}$ Kedua, aksara Lontara' Bugis ini menjadi bahasa utama di dalam pengajian kitab kuning (mangaji kitta') di setiap selesai Shalat Magrib dan Subuh pada Pondok Pesantren As'adiyah sampai saat ini. Di dalam pengajian kitab para santri menerjemahkan teks bahasa Arab kata-perkata dengan menuliskan terjemahannya di atas teks bahasa Arab. Dalam tradisi masyarakat, hal ini dikenal dengan istilah makna gandul. ${ }^{18}$

\section{C.2. Antara tarjamah dan tafsīr}

Pada dasarnya, kitab Tafsìr al-Qur'ān al-Karīm bi al-Lugah al-Bugīsiyyah tidak dapat sepenuhnya dikategorikan sebagai kitab tafsir, karena kitab ini pada dasarnya adalah terjemahan. Di sisi lain, untuk dikategorikan sebagai kitab terjemah juga tidak sepenuhnya tepat karena terjemahan AG. Yunus disertai dengan sejumlah keterangan tafsir di banyak ayat. Misalnya, pada QS. al-“Alaq: 19 kata "wasjud” tidak diartikan dengan kata "sujud” tetapi diartikan dengan "shalat" ( $)$ !

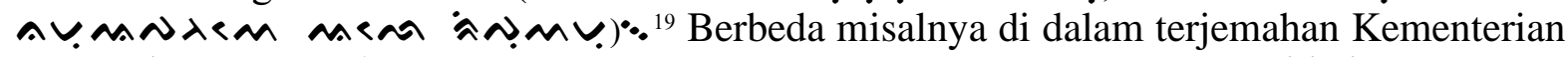
Agama kata "wasjud" masih tetap di artikan dengan makna "sujud". Seperti halnya dengan

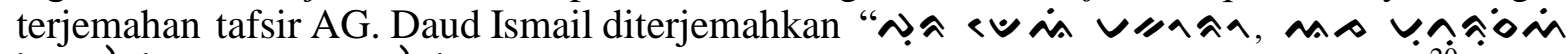

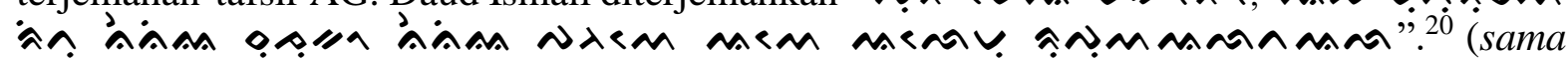

\footnotetext{
${ }^{17}$ Menurut penulusuran penulis bahwa aksara daerah di Indonesia yang masih ditemukan di beberapa daerah misalnya; aksara Jawa dengan Wonocoroko, aksara Lampung dengan Ulu Rejang, aksara Bali dengan Wianjana, aksara Sumbawa dengan Setera Jontal, aksara Kalimantan Barat/Serawak dengan Iban Alfabet, aksara Batak.

${ }^{18}$ Makna Gandul adalah penerjemahan teks bahasa Arab kata perkata dengan cara menuliskan terjemahan teks tepat di bawah teks yang bersangkutan dengan menggunakan huruf Arab (Arab Pegon). Makna Gandul ini menurut data yang ada pertama kali diperkenalkan oleh Muhammad Șāiḥ 'Umar al-Samārāni atau lebih dikenal dengan sebagai Kyai Sholeh Darat (1820- 1903). Aksara Arab Pegon adalah tulisan berbahasa Jawa menggunakan huruf Arab. Lihat Muh. Nur Ichwan, 'Negara, Kitab Suci, dan Politik Terjemah Resmi al-Qur'an di Indonesia" dalam Hendri Chambert-Loir (ed.) Sadur; Sejarah Terjemahan di Indonesia dan Malaysia (Jakarta: Gramedia Psutaka Utama, 2009), 415.

${ }^{19}$ Muhammad Yunus Maratan, Tafsir al-Qur'an, 19.

${ }^{20}$ Daud Ismail, Tafsir al-Munir, Juz 30 (Ujungpandang: CV. Bintang Selatan, t.th), 237.
} 
sekali tidak seperti itu, janganlah kamu patuhi, sujudlah dan dekatakanlah dirimu pada Allah). AG. Daud pada kata "wasjud" tetap diartikan dengan makna lafaz "sujud", meskipun sebenarnya yang dimaksudkan dengan "sujud" adalah shalat karena dengan shalat itulah sebagai sarana bagi seorang hamba bisa lebih dekat kepada Allah. Demikian pula beberapa ulama tafsir kata "wasjud" tetap diterjemahkan dengan makna "sujud". Namun, semuanya menafsirkan dengan penafsiran dengan makna "shalat" seperti halnya misalnya M. Quraish Shihab di tafsirnya. ${ }^{21}$ Dengan demikian, karya AG. Yunus ini lebih tepat dikategorikan sebagai model Tarjamah Tafsiriyah, kombinasi antara tafsir dan tarjamah.

\section{C.3. Metode Penyajian Vernakularisasi al-Qur'an dalam Tafsir AG. Yunus Maratan}

Salah seorang di antara ulama senior di tanah Bugis ${ }^{22}$ yang telah melakukan upaya vernakulasasi al-Qur'an adalah AG. Yunus Maratan dengan membuat karya tafsir ke dalam bahasa Bugis, yaitu Tafsīr al-Qur'ān al-Karìm bi al-Lugah al-Bugīsiyyah." Usahanya itu direspons oleh masyarakat dalam rangka memudahkan mereka dalam memahami makna alQur'an di kalangan masyarakat Bugis yang notabene dari kalangan masyarakat awam terhadap literatur bahasa Arab. Apalagi dalam konteks sosial budaya masyarakat Bugis pada saat itu bahasa Bugis juga digunakan sebagai bahasa pengantar di dalam pengajaran pada madrasahmadrasah di Pondok Pesantren As'adiyah Sengkang. Pada saat itu masyarakat Bugis pada umumnya 'kurang mampu' atau masih sangat minim untuk bisa membaca literatur yang berbahasa Indonesia apalagi yang berbahasa Arab dalam memahami al-Qur'an. Beliau mengungkapkan dalam pendahuluan kitabnya (versi cetakan pertama, terbit 9 Oktober 1958) sebagai berikut:

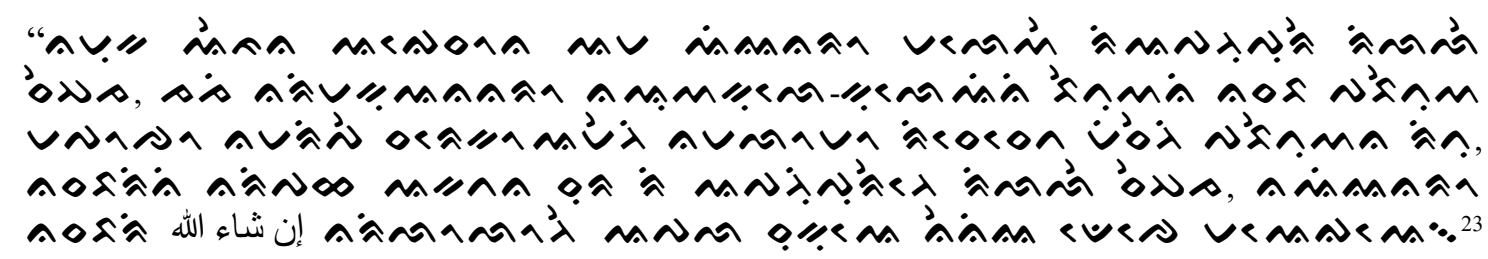

(Dengan adanya juz Amma, di mana pada umumnya dibaca setelah surah al-Fatihah di dalam shalat, maka saya berupaya sekuat tenaga untuk menerjemahkan dengan terjemah yang singkat dan sederhana agar supaya orang yang membaca dalam shalat mudah memahami makna surah (yang dibaca) sehingga Insya Allah bisa mendapatkan pahala yang sempurna dan pahala yang banyak).

Kemudian pada cetakan ke-3 yang diterbitkan pada tahun 1972 M/1392 H terdapat sedikit penambahan pada bagian pendahuluannya yaitu:

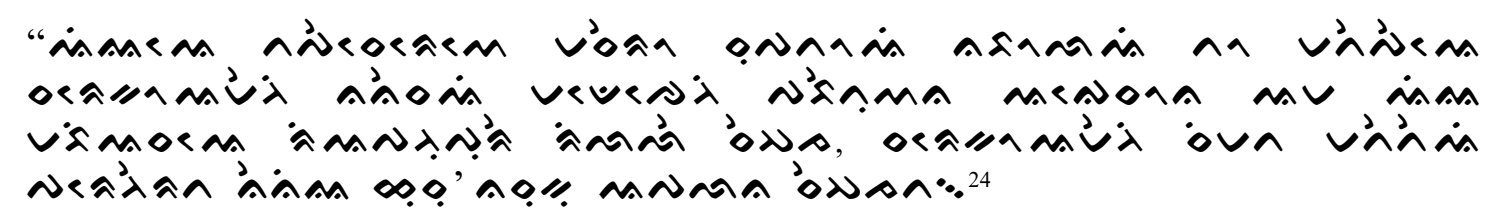

${ }^{21}$ M. Quraish Shihab, Tafsir al-Misbah; Pesan dan Keserasian al-Qur'an, Vol. 15, (Tangerang: Lentera Hati, 2017), 418.

${ }^{22}$ Ada beberapa karya al-Qur'an yang ditulis oleh ulama Bugis, baik berupa terjemahan maupun karya tafsir, misalnya "Terjamah al-Qur'an Bahasa Bugis” 30 juz karya Hamzah Manguluang, "Tafsir al-Qur'an bi al-Lugah Bugisiyah” Karya Muh. As'ad, "Tafsir al-Munir”, karya Daud Ismail, Tafsir MUI Sulsel (Tafsir al-Mu'in), karya Muin Yusuf. Mursalim, "Tafsir Bahasa Bugis Karya MUI Sulawesi Selatan (Analisis Metodologis Penafisran alQur'an)" Jurnal Lentera Dakwah dan Komunikasi XVI, no. 2 (2014). Lihat juga Abd. Kadir M, Tafsir Lokal Hari Ini dari Eksistensi hingga Persepsi (Yogyakarta: Arti Bumi Intaran, 2015).

${ }^{23}$ Muhammad Yunus Maratan, Tafsir al-Qur'an al-Karim bi al-Lugah al-Bugisiyyah, (Sengkang: Toko Buku Adil, 1972), 3.

${ }^{24}$ Muhammad Yunus Maratan, Tafsir al-Qur'an al-Karim, 4. 
(Tafsir ini sudah sepantasnya dimiliki oleh orang yang beriman agar supaya dapat memahami dengan baik terjemah juz Amma, di mana pada umumnya mereka menjadikan bacaan surah dalam shalat (pappanguppu) setelah surah al-Fatihah, sehingga shalatnya dilaksanakan dengan baik dan senantiasa ingat kepada Allah atau khusyu').

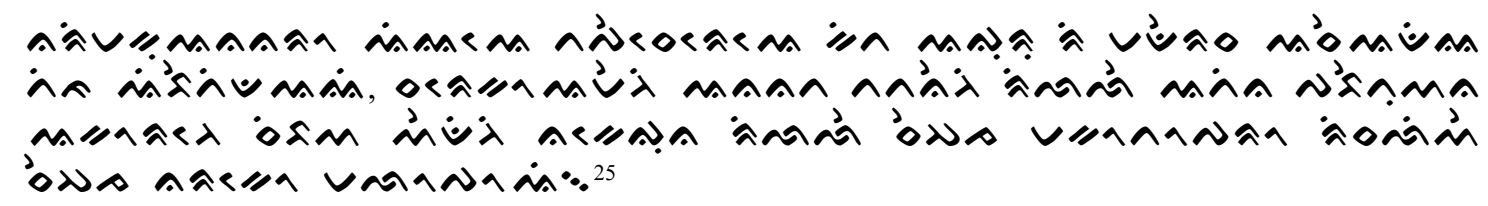

(oleh karena itu, tafsir ini adalah sebuah kitab pelajaran (diktat/muqarrar) di Madrasah Ibtidaiyah As'adiyah, agar anak-anak kita senantiasa tertanam di dalam hatinya makna alQur'an dan dapat digunakan, baik di dalam shalat maupun di luar shalat saat nanti sudah dewasa).

Dari pengantar yang dikemukakan di atas jelas bahwa kehadiran tafsir singkat ini merupakan suatu upaya yang luhur dan mulia AG. Yunus dalam rangka umat Islam bisa memahami makna-makna ayat al-Qur' an melalui bantuan terjemahan ini, tidak hanya sekedar sebuah bacaan belaka dalam shalat tetapi juga menjadi penerang jalan bagi mereka di dalam kehidupan sehari-harinya. Karena dengan tafsir pengantar bahasa Bugis masyarakat awam yang kurang mampu membaca buku-buku yang berbahasa Indonesia dapat terbantu untuk memahami makna al-Qur'an.

Penambahan redaksi motivasi pada cetakan ketiga itu di samping bertujuan untuk memudahkan masyarakat Bugis yang awam dalam memahami kitab suci al-Qur'an, khususnya bacaan dalam shalat, juga sebagai kitab pelajaran bagi anak- anak sekolah Madrasah Ibtidaiyah As'adiyah, baik yang berada di kota Sengkang maupun di cabang-cabang Madrasah As'adiyah yang ada di daerah yang juga masih setia dengan penggunaan bahasa Bugis sebagai bahasa pengantar di dalam pengajarannya.

\section{Dialektika Tafsir AG. Yunus dalam Bingkai Budaya Bugis}

Upaya penafsiran al-Qur'an telah berjalan sejak kitab suci ini turun kepada Rasulullah saw. Ketika itu, Rasulullah sendiri yang merupakan orang pertama menjelaskan maksud alQur'an kepada umat Islam. Setelah Nabi wafat penafsiran berlanjut di kalangan para sahabat, tābi'in, ulama sampai seterusnya yang bersambung dari generasi ke generasi hingga saat ini yang dilakukan oleh para ulama tafsir. Tentunya usaha penafsiran al-Qur'an yang dilakukan oleh para ulama tersebut telah terjadi perbedaan, baik dari segi metode atau cara, pendekatan, warna tafsir bahkan perbedaan pendapat.

Munculnya perbedaan penafsiran penulis tafsir-paling tidak sedikit atau banyakdipengaruhi oleh sosial-kultural yang ada, sehingga wajar jika ditemukan berbagai macam karya tafsir yang lahir dari tangan para mufassir dengan gaya, corak dan metode yang berbedabeda. Sebagaimana diungkapkan oleh Ali bin Abi Țālib bahwa al-Qur'an diantarai dua sampulnya tidak bisa berbicara, akan tetapi yang membuat bisa berbicara adalah sang penafsir (al-Qur'ān baina diffatay al-mushhaf lā yantiq, wa innamā yatakallamu bihī al- rijāl. ${ }^{26}$ Bagaimanapun harus disadari bahwa tafsir al-Qur'an merupakan karya manusia yang tentu saja sang penulis tidak berada dalam dunia hampa, tetapi berada di dalam lingkup situasi dan kondisi zamannya, sehingga wajar jika sebuah produk tafsir tidak lepas dari proses dialektika antara penafsir dengan realitas sosial-budaya.

Dalam konteks tanah Bugis, Islam dan budaya Bugis merupakan dua eksistensi yang saling mengisi dan beradaptasi. Sulit memisahkan keduanya karena Islam diadaptasikan ke

${ }^{25}$ Muhammad Yunus Maratan, Tafsir al-Qur'an al-Karim, 4.

${ }^{26}$ Ahmad Fawaid Sjazili, “al-Qur'an dan Juru Bicara Tuhan”, Jurnal Tashwirul Afkar, no. 18 (2004). 
dalam wujud kehidupan keagamaan yang bernuansa Bugis, demikian sebaliknya budaya Bugis juga banyak dipengaruhi oleh nilai-nilai Islam. Misalnya, kata "siri" dalam bahasa Bugis berarti "rasa malu dan harga diri" berasal dari bahasa Arab "sirrun" yang bermakna "rahasia", karena hubungan antara siri' dan sirrun adalah karena munculnya rasa malu pada diri seseorang disebabkan salah satunya adalah karena adanya rahasia yang terungkap pada orang lain yang semestinya tidak terungkap. ${ }^{27}$

Bagi masyarakat Bugis, sebelum datangnya Islam dikenal dengan istilah pangadereng, yaitu suatu wujud kebudayaan yang mencakup sistem, norma, dan aturan-aturan adat serta tata tertib juga mengandung unsur-unsur yang meliputi seluruh kegiatan hidup manusia bertingkah laku dan mengatur prasarana kehidupan material dan non-material. ${ }^{28}$ Nilai-nilai ini bagi masyarakat Bugis-Makassar sangat dihormati dan dijunjung tinggi seperti kedudukannya dengan syariat (agama) itu sendiri. Jadi antara pangedereng dengan syariat tidak bisa dipisahkan sebagaimana dalam ungkapan :

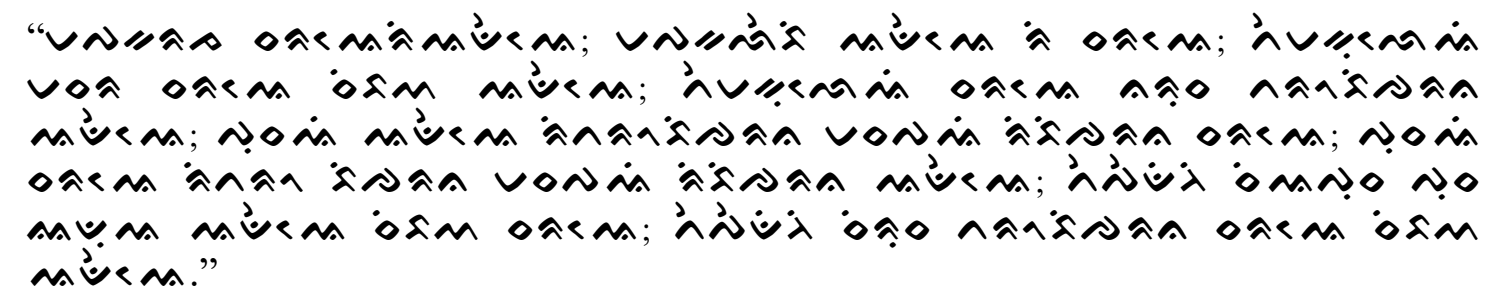

(Syariat menghormati adat Adat menghormati syariat; Adat dan syariat tidak dapat dipisahkan; Adat tidak boleh membatalkan putusan syariat; Syariat tidak boleh membatalkanutusan adat; Apabila adat tidak dapat memutuskan suatu perkara, maka ia mencari pada syariat; Apabila syariat tidak dapat memutuskan suatu perkara, maka ia mencarai pada adat; Adat dan syriat keduanya tidak boleh sesat-menyesatkan; Tidak boleh saling membatalkan keputusan antara adat dan dengan syariat.) Dengan demikian, kondisi sosio-kultutral dan sosio-politik serta disiplin ilmu yang dimiliki oleh seorang mufassir adalah merupakan suatu kondisi yang membentuk suatu paradigma dalam proses tafsir al-Qur'an. Demikianlah yang terjadi pada karya anregurtta Yunus sebagai sebuah karya yang tidak lepas dari konteks di mana tafsir ini di tulis.

Dalam tafsir anregurutta Yunus, peneliti menemukan setidaknya dua bentuk dialektika antara al-Qur'an dengan budaya Bugis, yaitu penggunaan aksara lontara dalam pengantarnya dan penyerapan bahasa al-Qur'an ke dalam bahasa Bugis. Sebagai karya terjemahan, kitab ini merupakan upaya memudahkan masyarakat Bugis dan santri-santri pesantren untuk dapat memahami makna-makna dasar ayat-ayat al-Qur'an, khususnya ayatayat yang sering dibaca sebagaimana yang terdapat pada juz Amma.

Pilihan bahasa Bugis sebagai bahasa pengantar di dalam tafsirnya merupakan suatu usaha yang dilakukan oleh anregurutta agar sebuah teks (ayat-ayat al-Qur'an) bisa memberikan makna bagi pembacanya. Pandangan ini sejalan dengan teori hermeneutika W. Dhelthey, sebuah teks ditafsirkan bukan hanya mencari pemahaman apa yang dimaksud oleh sebuah teks tetapi mencari apakah teks memberikan makna di masa kini. ${ }^{29}$

Pemilihan bahasa Bugis dalam karya anregurutta ini sebagai bahasa pengantarnya -

${ }^{27} \mathrm{Abu}$ Hamid, "Semangat Islam dalam Kebudayaan Orang Bugis-Makassar" dalam http://www.sttjaffray.ac.id/images/stories/kebudayaan.pdf, pada tanggal 08 Oktober 2020. Tasmin Tangngareng, "Upaya Pewarisan Budaya Siri' dalam Rumah Tangga di Kalangan Masyarakat Bugis-Makassar di Kota Makassar", Jurnal Sosiorelegius III, no. 1 (2017), 7-19.

${ }^{28}$ Mattulada, Latoa; Suatu Lukisan Analitis terhadap Antropologi Politik Orang Bugis, Yogyakarta: Universitas Gaja Mada Press, 1985, 306.

${ }^{29}$ Richard Palmer, Hermeneitucs; Interpretation Theory in Schlemarcer, Delthey, Heidegger and Gadamer (Envaston: Northwestern University Press, 1969), 68. 
secara umum seperti karya-karya lokal lainnya- merupakan hal yang lumrah, karena ketika itu bahasa Bugis menjadi bagian utama dalam komunikasi sehari-hari di tengah masyarakat. Ketika itulah para ulama Bugis pada umumnya menggunakan bahasa Bugis dalam menulis karya-karyanya, termasuk karya-karya anregurutta sekitar $98 \%$ pengantarnya menggunakan bahasa Bugis dan aksara lontara. Di samping itu, anregurutta Yunus sebagai pimpinan pesantren, di mana tradisi pengajaran/pengajian kitab-kitab klasik (kuning) dengan sistem halaqah tidak bisa terpisahkan dengan penggunaan bahasa Bugis dengan aksara lontara dalam menerjemahkan kitab-kitab tersebut.

Penggunaan Bahasa Bugis dalam karyanya tersebut bukan hanya sekedar persoalan teknis dan pragmatis seperti di atas, yaitu sebagai suatu sarana untuk menyampaikan gagasan terhadap penafsiran al-Qur'an, tetapi juga terkait dengan pemeliharaan unsur-unsur kebudayaan, tradisi, dan kepentingan masyarakat yang menjadi sasaran pembacanya. Dengan demikian, al-Qur' an bisa dipahami tidak hanya terbatas pada orang-orang yang paham bahasa Arab, tetapi juga bagi masyarakat awam yang hanya bisa membaca dengan bahasa Bugis.

Lokalitas Bugis bisa diakomodasi oleh anregurutta dalam penafsirannya dan pemilihan surat-surat pendek (Juz Amma) sebagai obyek kajiannya yang merupakan bacaan yang umum bagi masyarakat Islam pada saat itu, khususnya umat Islam Bugis. Bahasa Bugis menjadi bahasa untuk semua kegiatan kebudayaan masyarakat Bugis, sebagaimana juga digunakan dalam penyebaran agama Islam (dakwah), perdagangan, bahasa kesustraan ${ }^{30}$ dan kegiatan-kegiatan lainnya termasuk dalam bahasa sehari-hari di beberapa pesantren sebagai bahasa pengajaran, baik di sekolah apalagi dipengajian-pengajian (halaqah/mangaji tudang).

Penyerapan bahasa Arab (al-Qur'an) ke dalam bahasa Bugis yang dilakukan anregurutta misalnya penamaan surat-surat dalam kitab ini semuanya menggunakan versi bahasa Arab, kata al-Fatihah tidak diterjemahkan dengan artinya "pembuka" tetapi tetap diartikan dengan kata asalnya. Berbeda misalnya dalam tafsir AG. Muin Yusuf, justru namanama surat itu diartikan dengan arti versi bahasa Bugis, misalnya surat al-Baqarah diartikan dengan "surah sapi komba/sapi betina". Inilah kemudian yang dilakukan beberapa ulama Nusantara, termasuk ulama Bugis, yaitu melakukan usaha vernakularisasi (pembahasa lokalan) terhadap makna al-Qur'an sehingga bisa menjadi sebuah kitab yang shālih li kulli zamān wa makān (yang selalu kontekstual di segala waktu dan tempat). Apalagi usaha vernakularisasi al-Qur'an pada saat itu pernah terjadi perdebatan sengit seputar transliterasi Arab ke Indonesia dan bahasa lokal dianggap sebagai bid'ah bahkan menganggap haram dan kafir (halal darahnya) terhadap orang-orang yang menggunakan aksara latin untuk transliterasi huruf Arab.

Demikian pula istilah dalam ibadah, misalnya kata "puasa" dalam bahasa Bugis "mappuasa" dan kata zakat kemudian menajdi kata "massekke", sedekah menjadi "ma'sidekkah”. Berbeda halnya dengan kata 'shalat' dalam bahasa Bugis diterjemahkan

\footnotetext{
${ }^{30}$ Dalam kesusastraan Bugis dikenal dengan Sureq Lagaligo. Bagi masyarakat Bugis- Makassar, naskah I Lagaligo sebagai pustaka keramat atau sastra suci yang hanya dijumpai di rumah bangsawan wanita dan hanya mereka yang pernah tinggal di istana saja yang mahir membacanya. Menurut Informasi yang di dapat dari Fakhruddin bahwa naskah I Galigo tidak bisa sembarangan di simpan dan dibuka, karena hal itu dilakuakan, maka akan tejadi musibah sebagai alamat kemurkaan dewata atau tokoh yang ada dalam naska itu. Naskah Galigo harus dibungkus kain putih dan disimpan di sebuah rumah kemudian diletakkan di sisi tiang tengah dan orang tidur di dekatnya tidak bisa mengarahkan kakinya ke naskah tersebut. Bahkan naskah diyakini dapat menghindarkan diri dari segala macam kesulitan dan bencana. Sehingga masih banyak dibaca pada saat seseorang naik rumah baru, dan malam berjaga-jaga (maddoja) ketika hendak menabur benih atau pada saat perkawinan. Fakhruddin Ambo Enre, "Ritumpa'nna WelenranngE: Telaah Filologis Sebuah Episode Sastra Bugis Klasik Galigo" (Disertasi, Universitas Indonesia Jakarta, 1983), 21-22. Lihat juga dalam Andi Muhammad Akhmar, "Islamisasi Bugis Kajian Sastra atas Lagaligo Versi Bottinna La Dewata Sibawa We Attaweq" "Makalah" dalam Acara Diskusi Buku "Borobudur Writers and Cultural (BWC) Festival VII pada 22 November 2018 di Yogyakarta.
} 
"sempajang" yang justru diambil dari bahasa Indonesia. Contoh lain adalah penggunaan kata "Allah" dalam bahasa al-Qur'an, anregurutta memaknai dengan kata "puang Allah

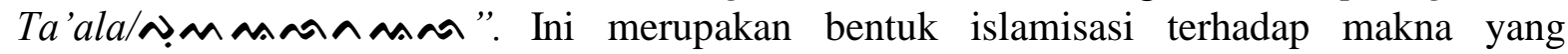
menunjukkan kepada Allah. Sebelum penggunaan kata puang Allah ta'alah bagi masyarakat Bugis, kata "Allah" yang menunjuk kepada Allah swt adalah kata "Dewata SeuwwaE", yaitu "Tuhan Satu". Dalam tradisi kepercayaan masyarakat Bugis sebelum datangnya Islam mereka sudah memiliki kepercayaan adanya Tuhan yang Esa. Dewa ini-menurut orang Bugisdiberikan dengan beberapa nama yaitu PatotoE (Dia yang menentukan nasib), Dewata SeuwaE (dewa yang tunggal), dan Turie A'rana (kehendak yang tertinggi). ${ }^{31}$ Sisa-sisa kepercayaan tersebut masih tampak jelas di masyarakat hingga saat ini di beberapa daerah, misalnya To Lotang di Sidenreng Rappang dan Kajang di Bulukumba.

Istilah Dewata SeuwaE dalam aksara lontara dibaca beberapa pengucapan misalnya, Dewata, Deewangta, dan De'watangna di mana mencerminkan sifat dan esensi Tuhan dalam pandangan teologi orang Bugis Makassar. Dee'wangta berarti "yang tidak punya wujud", "De'watangna" atau "De'batang" berarti yang tidak bertubuh atau yang tidak mempunyai wujud. De' artinya tidak, sedangkan watang (batang) berarti tubuh atau wujud. "Naiyya Dewata SeuwaE Tekkeinnang", artinya "Adapun Tuhan Yang Maha Esa itu tidak beribu dan tidak ber-ayah". Anregurutta menerjemahkan bismillah:

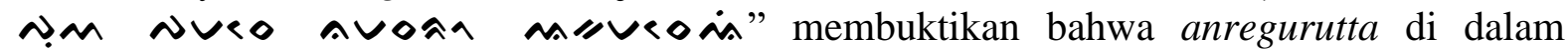
terjemahannya tidak lagi menggunakan kata yang dipakai oleh masyarakat Bugis sebelumnya dengan kata "Dewata SuewwaE", tetapi sudah menyesuaikan dengan penggunaan bahasa Islam.

Kata Puwang Allah Ta'ala dalam bahasa Bugis terdiri tiga suku kata yaitu "puwang dan Allah Ta'ala". Penggunaan ungkapan ini adalah salah bentuk usaha anregurutta dalam memelihara kearifan budayanya. Kata puwang sebuah kata yang bermakna "yang diperagungkan/dipertuankan" dalam tradisi Bugis kata ini digunakan ketika seseorang menyebut nama orang yang sangat dihormati atau panggilan bagi seorang bangsawan. Istilah puwang pada umumnya dipakai bagi masnyarakat Bugis Bone, sementara bagi masyarakat Wajo - di mana penulis tafsir ini tinggal- menggunakan dengan istilah "puang". Misalnya dalam ungkapan orang Bugis "ku tampaiki puwang/pung joppa ri bolae" (saya undang Puwang/Pung ke rumah), kata puang/pung adalah sebuah sapaan penghormatan kepada orang yang lebih dituakan atau memiliki strata sosial yang tinggi. ${ }^{32}$

Penggunaan aksara Lontara merupakan bagian dari merawat aksara tersebut agar tidak punah dan hilang di tengah masyarakat dengan hegemoni budaya asing. Hal ini dapat dibuktikan keseriusan beliau dalam melakukan vernakularisasi ilmu-ilmu keislaman ke dalam bahasa Bugis dengan karya-karya beliau yang hampir semuanya ditulis dalam bahasa aksara Lontara' Bugis. ${ }^{33}$ Dialektika antara karya tafsir dengan masyarakat Bugis dengan penggunaan aksara lontara Bugis sebagai media penafsiran al-Qur'an, yang dalam antropologi dipandang sebagai sebuah simbol yang tidak hanya bertujuan untuk mempermudah pembaca dalam mengakses dan memahami karya ini, tetapi juga menjadi motivasi untuk mempermudah

\footnotetext{
${ }^{31}$ Nasaruddin Umar, "Kepercayaan Dewata Sewwae Bugis Makassar (1), 30 Mei 2015 dalam https://inilah.com/mozaik/2207756/kepercayaan-dewata-sewwae-bugis-makassar-1

${ }^{32}$ Status sosial -paling tidak- terbagi atas dua kelompok, yaitu ascribed status dan acheved status. Ascriubed status adalah berkaitan dengan status 'yang dimiliki oleh seseorang dengan keturunan, gender, atau umur. Ascheved statsus berkaitan dengan status yang dimiliki karena melalui perolehan misalnya pendidikan, kekayaan atau umur. Dalam tradisi Bugis status ini disebut dengan istilah “abbatireng' (keturunan, tititsan) dan 'onrong' (tempat). Lihat Murni Mahmud, Politeness in Bugis, a Study in Linguistic Antrophology, Vol. I dan II, (Makassar: Badan Penerbit UNM, 2010), 9.

${ }^{33}$ Lihat karya AG. Yunus pada Bab III, karyanya sebanyak 35 buah, bahasa Bugis sebanyak 32, sementara dalam Bahasa Arab hanya 3 buah.
} 
memahami ayat-ayat al-Qur'an.

\section{E. Akulturasi Islam di Nusantara melalui Vernakularisasi Al-Qur'an}

Kedatangan Islam di bumi Nusantara tidak serta merta menghapus atau menggantikan tradisi-tradisi yang lama, tetapi Islam dengan ajaran universalitasnya sangat akomodatif terhadap nilai-nilai lokalitas. Sebagaimana tergambar di dalam al-Qur'an banyak ditemukan nuansa dialektika antara al-Qur'an dengan kultur masyarakat Arab. ${ }^{34}$ Fenomena islamisasi di Indonesia terjadi pada tiga bentuk pola yang dilakukan oleh para penyiar Islam, yaitu adopsi/apresiatif (tahmil), destruktif (tahrim), dan adopsi-rekonstruktif (tagyir). ${ }^{35}$ Salah satu di antaranya terjadi pada tradisi vernakulisasi atau penerjemahan dan tafsir al-Qur'an ${ }^{36} \mathrm{ke}$ dalam berbagai bahasa daerah di antaranya, Melayu (Arab-Pegon), ${ }^{37}$ bahasa Jawa, bahasa Sunda, dan bahasa Bugis. ${ }^{38}$

Penggunaan media bahasa daerah sebagai bahasa ibu dalam penulisan karya tafsir sebagai sebuah upaya agar pesan al-Qur'an lebih mudah tersampaikan kepada masyarakat pembacanya, atau mendomestikasi serta menjembatani jarak antara bahasa al-Qur'an dan bahasa lokal. ${ }^{39}$ Langkah itu dilakukan oleh para penyiar Islam dalam rangka upaya untuk memuluskan arus islamisasi yang lebih efektif dan efisien. Faktor itulah yang mendorong ulama Nusantara (Indonesia) menulis karya mereka ke dalam berbagai bahasa daerah. Hal yang sama juga dilakukan oleh beberapa ulama Bugis ketika memproduksi terjemahan dan penafsiran al-Qur'an ke dalam bahasa Bugis Lontara. ${ }^{40}$

\section{F. Penutup}

Metodologi penyusunan Tafsir al-Qur'an al-Karim/Tafesere Akorang Bettuwang Ogi yang ditulis oleh AG. Yunus Maratan disusun secara sistematis menggunakan bahasa lokal. Hal itu dapat dilihat dengan tetap mencantumkan teks aslinya (Arab) yang diletakkan secara simetris dengan terjemahnya, sehingga secara tidak langsung pembaca dapat dengan mudah mengetahui antara teks asli dan terjemahnya. Itulah sebabnya, karya ini dapat memberikan kontribusi yang sangat besar dalam membantu masyarakat awam dari kalangan Bugis untuk

\footnotetext{
${ }^{34}$ Syamsul Wathani "Dialektika al-Qur'an dengan Pola Pikir keberagamaan Masyarakat Arab; Analisis Psiko-Sosial” Indonesian Journal of Islamic Literature and Muslim Sociaty 1, no. 2 (2016), 181-198.

${ }^{35}$ Ali Sodiqin, Antropologi Al-Qur'an; Model Dialektika Wahyu dan Budaya (Jogyakarta: Ar Ruzz Media, 2008). Bandingkan dengan Husaini Husda, "Islamisasi Nusantara (Analisis terhadap Diskursus Para Sejarawan) Jurnal Adibiya 18, no. 2 (2016), 17-29.

${ }^{36}$ Adalah upaya pengalihan karya-karya bahasa Arab ke Bahasa lokal. Menurut Anthny H. Johns bahwa sejak pertengahan abad ke-16 di wilayah Nusantara telah terjadi vernakularisasi karya ulama. Anthony H. Johns, "Quranic Exigesis in the Malaya Word" dalam Abdullah Saeed (ed.), Aproaches to the History of the Interpretation of the Qur'an (New York: Oxford University Press, 2006). Lihat juga dalam Mursalim, "Vernakularisasi al-Qur'an di Indonesia; Suatu kajian Sejarah Tafsir al-Qur'an), “Lentera Jurnal Dakwah dan Komunikasi” XVI, no. 1 (2014).

${ }^{37}$ Arab Pegon adalah tulisan yang menggunakan huruf Arab atau huruf hijaiyah tetapi lafaznya adalah bahasa Jawa atau Melayu atau Indonesia. Kata Pegon berasal dari bahasa Jawa "pego" yang artinya "ora lumrah anggone ngucapake/ tidak lazim dalam pelafalannya”. Sri Wahyuni dan Rustam Ibrahim, "Pemaknaan Jawa Pegon dalam Memahami Kitab Kuning di Pesantren” Jurnal Studi Islam Manarul Qur'an, 17, no. 1 (2017), 421; Suarni, "Karakteristik Tafsir Tarjuman Mustafid” Substantia, 17, no. 2, (2015), 159-166.

${ }^{38}$ Islah Gusmian, “Tafsir al-Qur'an Bahasa Jawa; Peneguhan Identitas, Ideologi, dan Politik” Jurnal Kajian al-Qur'an Suhuf 9, no. 1 (2016).

${ }^{39}$ Benjamin B Zimmer, “Al- 'Arabiyyah and Basa Sunda; Ideologis of Trnaslation and Interpretation among the Moslems of Wets Java", dalam Jurnal "Studia Islamika”, 7, no. 3 (2000): 3.

${ }^{40}$ Istilah Lontara' merupakan naskah atau manuskrip (tulisan) yang memberikan gambaran budaya mereka (orang Bugis) di masa silam, ditulis dengan berupa alat yang tajam (seperti pena/) di atas daun lontar (rontal) dan dibubuhi dengan cairan warna hitam pada bekas goresan. Seiring dengan perkembangan kertas ditemukan, bergeserlah daun lontar sebagai alat tulis digantikan dengan kertas. Namun, tulisan naskah masih tetap disebut dengan nama tulisan lontara'. Bahri, Andi Dewi Riang Tati, "Lontarak; Sumber Belajar Sekolah Sulawesi Selatan" dalam Jurnal Pendidikan Sejarah, 8, no. 1 (2019); 51.
} 
dapat berdialog dengan al-Qur'an, sehingga mereka lebih mudah mengakses makna-makna dasar yang terkandung di dalamnya. Di samping itu, AG. Yunus tidak hanya memproduksi wacana keislaman pada tataran oral (ceramah-ceramah) semata, tetapi juga mampu menyajikan berbagai karya tulis dari berbagai disiplin keilmuan.

Karya ini memberikan sebuah dialektika antara al-Qur'an dengan budaya Bugis, terlihat dari segi penggunaan bahasa sebagai bahasa pengantarnya dan penggunaan aksara Lontara' Bugis. Demikian pula dari segi pemilihan bahasa atau kata di dalam terjemahan dengan melakukan islamisasi terhadap bahasa Bugis atau perpaduan antara bahasa al-Qur'an dengan bahasa Bugis itu sendiri. Walaupun demikian, penelitian ini belum sampai pada kajian komparasi dengan berbagai karya ulama Bugis lainnya, sehingga ke depannya, objek kajian semacam itu penting dilakukan dalam rangka mengetahui kesatuan atau tidaknya metodologi yang mereka gunakan.

\section{DAFTAR PUSTAKA}

Abunawas, Kamaluddin \& Husnul Fahimah Ilyas. Menguak Cakrawala Perubahan; Kiprah AG. H. M. Yunus Martan dan AG.H. Abdullah Martan. Yogyakarta: Trusmedia Grafika, 2017.

Ambo Enre, Fakhruddin. "Ritumpa'nna WelenranngE: Telaah Filologis Sebuah Episode Sastra Bugis Klasik Galigo". Disertasi, Universitas Indonesia Jakarta, 1983.

H. Johns, Anthony. "Quranic Exigesis in the Malaya Word" dalam Abdullah Saeed (ed.), Aproaches to the History of the Interpretation of the Qur'an. New York: Oxford University Press, 2006.

Ismail, Daud. al-Ta'rif Bi al-Alim al-Allamah al-Syedkh al-Haj Muhammad As'ad al-Buqisi. Sengkang Wajo, 1956.

--------, Tafsir al-Munir. Ujungpandang: CV. Bintang Selatan, t.th.

Kadir M, Abd. "Transformasi kelekturan pada Pesantren As'adiyah" dalam Abd. Aziz Albone (ed.), Transformasi Kelekturan Pesantren di Sulawesi Selatan. Ujungpandang: Balai Penelitian Lektur Keagamaan, 1993.

Tafsir Lokal Hari Ini dari Eksistensi hingga Persepsi. Yogyakarta: Arti Bumi Intaran, 2015.

Karyra Tulis Ulama di Sulawesi Selatan, Proyek Pembinaan Perguruan Tinggi Agama IAIN Alauddin Ujungpandang, 1981/1982.

Mahmud, Murni. Politeness in Bugis, a Study in Linguistic Antrophology. Makassar: Badan Penerbit UNM, 2010.

Mattulada. Latoa; Suatu Lukisan Analitis terhadap Antropologi Politik Orang Bugis. Yogyakarta: Universitas Gaja Mada Press, 1985.

Nur Ichwan, Muh. "Negara, Kitab Suci, dan Politik Terjemah Resmi al-Qur'an di Indonesia" dalam Hendri Chambert-Loir (ed.) Sadur; Sejarah Terjemahan di Indonesia dan Malaysia. Jakarta: Gramedia Pustaka Utama, 2009.

Palmer, Richard. Hermeneitucs; Interpretation Theory in Schlemarcer, Delthey, Heidegger and Gadamer, Envaston: Northwestern University Press, 1969.

Shihab, M. Quraish. Tafsir al-Misbah; Pesan dan Keserasian al-Qur'an. Tangerang: Lentera Hati, 2017.

Sodiqin, Ali. Antropologi Al-Qur'an; Model Dialektika Wahyu dan Budaya. Jogyakarta: Ar Ruzz Media, 2008.

Al-Qațtān, Mannā' bin Khalīl. Mabāhisis Fī 'Ulūm Al-Qur'Ān. Riyāḍ: Maktabah al-Ma'ārif, 2000.

Lajnah Pentashihan Mushaf al-Qur'an Badan Litbang dan Diklat Kementerian Agama RI. Tafsir Ringkas al-Qur'an al-Karim, 2016.

Yunus Maratan, Muhammad. Tafsir al-Qur'an al-Karim bi al-Lugah al-Buqisiyah. Toko Buku 
Adil: Sengkang, 1972.

Al-Żahabī, Muḥammad Ḥusain. At-Tafsīr Wa Al-Mufassirūn. Kuwait: Dār an-Nawādir, 2010. Al-Zarqani, Muhammad Abd al-'Az̄̄̄m. Manahil al-Irfān fī 'Ulūm al-Qur'an. Beirut: Dar alFikr, 1996.

Aguswandi, "Kontribusi AGH. Muhammad As'ad terhadap Pengembangan Dakwah di Sengkang Kab. Wajo (Suatu Kajian Tokoh Dakwah), dalam Jurnal "al-Khitabah V, no. 2, (2018).

Awwaliyah, Neny Muthi'atul, and Idham Hamid. "Studi Tafsir Nusantara: Kajian Kitab Tafsir AG. H. ABD. Muin Yusuf (Tafsere Akorang Ma'basa Ugi).” Jurnal Studi Alquran dan Tafsir di Nusantara 4, no. 2 (2019): 138-154.

Bahri, Andi Dewi Riang Tati, "Lontarak; Sumber Belajar Sekolah Sulawesi Selatan" dalam Jurnal Pendidikan Sejarah 8, no. 1 (2019).

Gusmian, Islah. "Tafsir al-Qur'an Bahasa Jawa; Peneguhan Identitas, Ideologi, dan Politik" Jurnal Kajian al-Qur'an Suhuf 9, no. 1, 2016.

Husda, Husaini "Islamisasi Nusantara (Analisis terhadap Disursus Para Sejarawan)" Jurnal Adibiya 18, no. 2, 2016.

Muhammad Akhmar, Andi. "Islamisasi Bugis Kajian Sastra atas Lagaligo Versi Bottinna La Dewata Sibawa We Attaweq" "Makalah" dalam Acara Diskusi Buku "Borobudur Writers and Cultural (BWC) Festival VII pada 22 November 2018 di Yogyakarta.

Mursalim, "Tafsir Bahasa Bugis Karya MUI Sulawesi Selatan (Analisis Metodologis Penafisran al-Qur' an)" Jurnal Lentera Dakwah dan Komunikasi XVI, no. 2 (2014).

--------, "Vernakularisasi al-Qur'an di Indonesia; Suatu kajian Sejarah Tafsir al-Qur'an), "Lentera Jurnal Dakwah dan Komunikasi"” XVI, no. 1 Januari (2014).

---------, "Pemikiran Tasawuf Anregurutta H. Abdurrahman Ambo Dalle; Telaah atas Kitab al-Quwl al-Shadiq" Jurnal Fenomena 7, no. 2 (2015).

Nur, Moh Fadhil. "Vernakularisasi Al-Qur'an Di Tatar Bugis" Rausyan Fikr: Jurnal Studi Ilmu Ushuluddin dan Filsafat 14, no. 2 (2018): 359-394.

Sjazili, Ahmad Fawaid, “al-Qur'an dan Juru Bicara Tuhan” Jurnal Tashwirul Afkar, No. 18 (2004).

Suarni, “Karakteristik Tafsir Tarjuman Mustafid” Substantia 17, no. 2 (2015).

Tangngareng, Tasmin, "Upaya Pewarisan Budaya Siri' dalam Rumah Tangga di Kalangan Masyarakat Bugis-Makassar di Kota Makassar” Jurnal Sosiorelegius III, no. 1 (2017).

Wahyuni, Sri, dan Rustam Ibrahim, "Pemaknaan Jawa Pegon dalam Memahami Kitab Kuning di Pesantren" Jurnal Studi Islam: Manarul Qur'an 17, no. 1 (2017).

Wathani, Syamsul, "Dialektika al-Qur'an dengan Pola Pikir keberagamaan Masyarakat Arab; Analisis Psiko-Sosial" Indonesian Journal of Islamic Literature and Muslim Society 1, no. 2 (2016).

Zimmer, Benjamin B, "Al-'Arabiyyah and Basa Sunda; Ideologis of Translation and Interpretation among the Moslems of Wets Java" Studia Islamika 7, no. 3 (2000).

Halim, Wahyuddin, "Arung, To Panrita, dan Transformasi Otoritas Keagamaan dan Kecendikiwanan di Sulawesi Selatan, "Diskusi Buku Chirstian Pelras, Manusia Bugis, (Jakarta: Nalar 2006), oleh Yayasan Ininnawa: Pusat Kajian Budaya, pada tanggal 1416 Maret 2006 di UNHAS.

, "Refleksi Ramadhan; Mengapa Masjid Agung Darussalam Wajo Didatangi Pencari Berkah dari Luar Dearah? Tribun Timur.com tanggal 23 Mei 2018. 